\title{
An Overview of Teacher Ethics and Professionalism at Universities
}

\author{
Julius Tunsaje Tweve \\ Tumaini University Dar es Salaam College - TUDARCo
}

How to cite this paper: Tweve, J.T. (2019). An Overview of Teacher Ethics and Professionalism at Universities. The Educational Review, USA, 3(11), 187-193.

http://dx.doi.org/10.26855/er.2019.11.003

*Corresponding author: Julius Tunsaje Tweve, Tumaini University Dar es Salaam College - TUDARCo.

Email: julius.tweve@tudarco.ac.tz

\begin{abstract}
A professional is held in high regard because they are more experienced than the client a teacher is among them. To ensure that students' behaviours do not jeopardize their future careers, teachers must understand the activities that present ethical and professional issues and make every effort to educate students about appropriate behavior. For teachers, perhaps the most familiar unethical issue facing students is that of academic dishonesty. Teacher professionalism has relevant significance in education in that it affects the role of the teacher and his or her pedagogy, which in return affects the student's ability to learn effectively. This paper presents a link of ethics and teacher performance so as to add new ways on how teachers will be imparted with new dimensions to address and enhance professionalism in their day today activities. The paper discusses fundamental features a teacher is required to have in order to enhance teachers performance and quality assurance at large. The paper concludes by providing impact of unethical teacher and recommends on how to alleviate the situation.
\end{abstract}

\section{Keywords}

Teacher Ethics and Professionalism at University

\section{Introduction}

Professionalism is not commercialism; to be a professional, is to use education, experience and training to do work, anaylse, problem solve and make sound decisions Donald at el (1999). A professional must know and deliver sound advice to the client based on accumulated knowledge. A professional is held in high regard because they are more experienced than the client. Commercialism is the use of marketing and advertising to sell products and services regardless of the needs and requirements of a customer. The reality of doing business is that many companies choose commercialism over professionalism. In business, the drive is to make money supersedes the passion to deliver quality, professional services (Garet 2001). In education sector, this should be contrary to it, teachers are supposed to maintain quality of education.

After independence, teaching profession in Tanzania was one of the recognized and respected professional by leaders and community at large. Currently, teachers, at almost all levels of the education system in Tanzania, have been increasingly being implicated in all sorts of professional misconduct, ranging from sex-related behaviours, corrupt practices, use of impolite language, alcoholism, and abuse of other intoxicants, animosities and fights (Anangisye and Barrett, 2005)

Similarly, a completed definition of teacher professionalism far exceeds the simple notion that a teacher be prepared in a certain manner. A professional is trained to handle all situations, as most episodes in the classroom require quick thinking. Teacher professionalism extends beyond one's ability to understand content; the educator must discover if the students are being reached in an effective way. With the role of "teacher" becoming more autonomous, an educator must be competent in their studies, perform well under the eye of the administration, parents, and other stakeholders while maintaining good conduct to facilitate quality communication and education development (Allen 2010). Hence, 
there is a need to introduce information ethics into teacher education and or curricular.

Information ethics in Africa is a young academic field; not much has been published on the role that African philosophy can play in thinking about the challenges arising from the impact of ICT on African societies and culture (Capurro 2006). A professional has legitimate moral obligations to make sure professionalism is adhered to in decision making. Amunga (2013) noted that introduction of information ethics in the curriculum at Kenyatta University will have contribution to behaviour change, improve quality and quantity but also will curb the inadequate of communication skills course. She further pointed out the role of information ethics that it will help to curb plagiarism, add value to the quality of education and help in upholding ethical practices. The paper note the need to introduce or integrate Information Ethics courses in teacher education curricular both in secondary schools and higher learning institutions.

\section{Professional ethics}

The professional carries additional moral responsibilities to those held by the population in general and in society. This is because professionals are capable of making and acting on an informed decision in situations that the general public cannot, because they have not received the relevant training Barret (1998). Ethics are rules and values used in a professional setting (Changing Minds,). In the workplace managers and supervisors should set the standard for using ethics by showing respect, being honest, and promoting trust. If the management team uses unethical forms of communication, the team and business can fail. Ethics are used world-wide in large companies and small businesses. Promoting ethics in the workplace gives employees a sense of worth and trust that can help the business and employees succeed (Joseph and Joshua, 2000). This additional knowledge also comes with authority and power, teachers are not supposed to rely on tuition and bribe practices in order to gain more money and spend little time in normal scheduled classes (Anangisye 2010).

Ethics in Tanzania has a long history particularly from 1961 to 1985; ethics has been changing due to presidency (Tweve, 2012). During the late President Julius K. Nyerere 1961 to 1985 ethics among public servants was strongly observed and maintained due to Arusha Declaration. Ishumi (2009) and Kaduma, (2010), argue that in Tanzania, professional ethics is an overlooked but critical factor in complying with standards in all sectors. Tanzania code of ethics for teachers is in place to guide and control teacher professionalism (Anangisye, 2006). Other sectors such as Medical ethics under the Medical Association of Tanzania and Tanganyika Law Society are some of the organs which oversee professionalism.

\section{Teacher education}

Teacher education refers to the policies and procedures designed to equip prospective teacher with the knowledge, attitudes, behaviours, and skills they require to perform their tasks effectively in the classroom, school and wider community. Curriculum the question of what knowledge, attitudes, behaviours and skills teachers should possess is the subject of much debate in many cultures Garet et al (2001). This is understandable, as teachers are entrusted with the transmission to learners of society's beliefs, attitudes and deontology, as well as of information, advice and wisdom, and with facilitating learners' acquisition of the key knowledge, attitudes and behaviours that they will need to be active in society and the economy. In order to achieve this, the content of information ethics should be added in teacher education curricular urgently.

\section{Teachers' Professionalism}

Teacher professionalism has relevant significance in education in that it affects the role of the teacher and his or her pedagogy, which in return affects the student's ability to learn effectively. It can be defined as the ability to reach students in a meaningful way, developing innovative approaches to mandated content while motivating, engaging, and inspiring young adult minds to prepare for ever-advancing technology. However, this definition does little to exemplify precisely how a professional teacher carries himself or herself Anangisye and Barrett (2005). Due to the growing autonomy being given to educators, professionalism remains one of the most influential attributes of education today; teacher professionalism contains three essential characteristics, competence, performance, and conduct. These reflect the educator's goals, abilities, and standards, and directly impact the effectiveness of teaching through the development of qualities. Information ethics should be added to strengthen teaching profession.

\section{Teachers' competence}

The characteristic of competence is fundamental in an educator's pursuit of excellence; a discussion on competence focuses on three important ideas: preparation, knowledge of subject area, and defined pedagogy. The first, preparation, 
prepares the professional for the adversity of the classroom. From language and cultural barriers to socio-economic differences, all educators face deterrents in the classroom that must be broken down by individualized techniques. "Decision making by well-trained professionals allows individual clients' needs to be met more precisely and promotes continual refinement and improvement in overall practice" (Barrett 2005). In Tanzania, this situation is reflected in teachers curricular both in teachers training colleges and universities (Anangisye 2010). Thus, by bridging these barriers, the educator will be better prepared for classroom management and create an effective learning environment. Furthermore, by doing this, the professional teacher leads students by his or her example: one who is prepared for difficulties will be able to overcome them. Primary, secondary schools and colleges by then self-reliance ideology was emphasized in education programmes.

Knowledge base. Along with preparation, a professional educator with a strong knowledge of his/her subject area has the opportunity to concern themselves with preparing innovative techniques to teach material rather than spending significant amounts of time studying the material Brian and Steven (2003). With the advantage of knowing one's curriculum material well, the educator has more confidence in their teachings, having already placed significant thought on the material being taught. Thus, a professional is able to dwell on how to relate subject matter to the students and their cultures in an original method.

Pedagogy. The final portion of competence is discovering and assuming a defined pedagogy. A professional teacher who has a defined pedagogy has already journeyed through several trials to discover which pedagogical techniques are most effective. According to Quinn (2000), hiring teachers by subject and skill presumes that curricular priorities have been established, which means that decisions have been made about how much time will be devoted to each segment of the curriculum. Although this may take years to fine-tune, a professional is willing to self-evaluate his or her pedagogy as s/he develops it, revise their edification when deemed necessary, and apply one's ideas to a practical situation. Furthermore, by acquiring a defined pedagogy and information ethics, a professional creates more autonomy for him or herself, allowing for a partial release from the constraints constructed by the administration, school board, or parents.

\section{Teachers, performance}

Note that, competence is essential to teacher professionalism; it is only useful if the educator is able to perform. Performance is the ability to effectively teach the concepts of a curriculum. However, this is performance defined at its most fundamental level. "As individuals, professionals have the right to perform their work as they see fit, based on knowledge acquired through specialised training" (Schnall 2009) such a quote demonstrates the essentiality of performance, which derives from both premeditated and improvisational techniques.

Application. A professional teacher educates so that students learn concepts and apply them to their lives. Although this undermines the school's emphasis on state test results, a quality educator prepares for the tests through this unique style of applying to his/her students' lives. Thus, the application of these concepts must be inside the bounds of students' lives.

Dedication. Furthermore, an educator that has a high standard of performance is reliable and dedicated. This type of educator becomes an active teacher rather than a passive teacher, showing the students a genuine interest in their progress as a student. Lack of dedication of teachers may cause a lot of problems i.e. form four results 2013 in Tanzania more than half of students failed, this one of indicators of lack of dedication among teachers because of low salaries.

\section{Teachers' conduct}

The final characteristic of teacher professionalism, conduct, is equally as significant as the first two. The manner in which an educator carries himself or herself is a reflection on one's classroom, school, community, and educational system. Conduct is a representation of how well one takes care of himself or herself, from aesthetics to language and behavior Allen (2010). However, these are minor qualities of conduct. Conduct also includes one's ability to initiate and maintain quality communication with all the parties involved in education: students, fellow teachers, school board, administration, and parents. It is through energetic communication by a professional that initiates understanding, whether it is a student grasping their potential or the professional voicing their displeasure on a newly implemented regulation. A professional teacher desires to locate effective communicative skills to achieve preferred educational goals.

\section{Ethical Teachers}

According to Anangisye and Barret (2005) point out a number of professional organisations and academic institutions define their ethical approach as a number of discrete components; typically these include:- 
Honesty. Honesty refers to a facet of moral character and denotes positive, virtuous attributes such as integrity, truthfulness, and straightforwardness along with the absence of lying, cheating or theft. Honesty travels on a larger arc than merely telling the truth. Telling the truth involves answering a question directly without lying or attempting to deceive. Honesty involves context and answering even the unasked question. Honesty means being open about one's life.

Integrity. Integrity is a concept of consistency of actions, values, methods, measures, principles, expectations, and outcomes. In ethics, integrity is regarded as the honesty and truthfulness or accuracy of one's actions. Integrity can be regarded as the opposite of hypocrisy in that it regards internal consistency as a virtue, and suggests that parties holding apparently conflicting values should account for the discrepancy or alter their beliefs. Integrity is the inner sense of "wholeness" deriving from qualities such as honesty and consistency of character. As such, one may judge that others "have integrity" to the extent that they act according to the values, beliefs and principles they claim to hold.

Transparency. Transparency implies openness, communication, and accountability. It is a metaphorical extension of a "transparent" object being one that can be seen through. Transparent procedures include open meetings, financial disclosure statements, freedom of information legislation. Budgetary review and audits; transparency is operating in such a way that it is easy for others to see what actions are performed. All organizations have a transparency culture, that part of the culture that relates to transparency; but few have a culture of transparency, i.e., a culture of being aware of transparency and incorporating it routinely into how things are done.

Accountability. Accountability is the concept in ethics and governance with several meanings. It is often used synonymously with such concepts as responsibility, answerability, blameworthiness, liability, and other terms associated with the expectation of account-giving Snow and Lauer (2005). Within an organization, the principles and practices of ethical accountability aim to improve both the internal standard of individual and group conduct as well as external factors, such as sustainable economic and ecologic strategies. Also, ethical accountability plays a progressively important role in academic fields, such as laboratory experiments and field research.

Confidentiality. Confidentiality is an ethical principle associated with several professions (e.g., medicine, law). In ethics, and (in some places) in law and alternative forms of legal resolution such as mediation, some types of communication between a person and one of these professionals are "privileged" and may not be discussed or divulged to third parties.

Respect. Respect denotes both a positive feeling of esteem for a person or other entity (such as a nation or a religion), and also specific actions and conduct representative of that esteem. Respect can be a specific feeling of regard for the actual qualities of the one respected (e.g., "I have great respect for her judgment"). It can also be conduct in accord with a specific ethics of respect. Rude conduct is usually considered to indicate a lack of respect, disrespect, whereas actions that honor somebody or something indicate respect. Specific ethics of respect are of fundamental importance to various cultures. Respect should not be confused with tolerance, since tolerance doesn't necessarily imply any positive feeling.

Apart from the above ethical elements, there challenges facing teachers not only in Tanzania but also regional and international. The quality of learning and competency level of both students and teachers in Tanzania is among the poorest in the region. One of the reasons is the low level of educational qualifications required to become a primary and secondary school teacher. Other challenges include poor certification, bullying in teaching, mobbing, and sexual harassment,

\section{Academic dishonesty}

Academic dishonesty or academic misconduct is any type of cheating that occurs in relation to a formal academic exercise. Anangisye (2010) listed some of misdemeanors mainly committed by teachers in different levels primary, secondary and universities include:- plagiarism, fabrication, deception, cheating, bribery, professional misconduct, impersonation and sabotage. Academic dishonesty has been documented in most every type of educational setting from elementary school to graduate schools. Throughout history this type of dishonesty has been met with varying degrees of approbation. Today, those who are a part of an educated society tend to take a very negative view of academic dishonesty. Information ethics is one the means to inculcate ethical practices among students and teachers.

Effects of academic dishonest; cheating in academia has a host of effects on students, on teachers, on individual schools, and on the educational system itself. Some of the effects are:- dishonest, lack of graduants' reputation, unproductive, emotional distress, lack of institutional reputation, lower down quality, poor learning atmosphere and loose identity and integrity.

\section{Deterrence or punishment}


Punishments for academic dishonesty vary according to the age of the party involved and the nature of the infraction. In high school, a standard penalty for cheating is a failing grade; in college, it can result in expulsion or dismissal (at Tumaini University for instance, there are no lesser penalties than dismissal for breaches of the honour code). In rare instances, professors all over the world have been fired when it was discovered that they plagiarized during college or graduate school. All parties involved in the dishonesty not just the individual whose grade is increased by it can be punished.

\section{Information ethics in Tanzania}

The extent of information ethics adherence in information services provision among information professionals in Tanzania is improving in one way or another. Information ethics adherence involve intellectual property, user privacy, accessibility, authenticity, currency, reliability, safety, security, integrity, accuracy, surveillance, impartiality, avoidance of plagiarism, confidentiality, avoidance of bias, access to information and transparency to mention a few. They involve in the creation, storage and dissemination of information. Lack of efficiency and effectiveness due to lack of ethics in the information management field is directly linked to the persistence of corruption and fraud (Tweve, 2012). Information professionals, like any other professionals need to abide by ethics and professionalism practices. Teachers, at almost all levels of the education system in Tanzania, have been increasingly being implicated in all sorts of professional misconduct, ranging from sex-related behaviours, corrupt practices, use of impolite language, alcoholism, and abuse of other intoxicants, animosities and fights (Anangisye and Barrett, 2005). Hoel and Cooper (2000) argue that lack of information ethics adherence among professionals hinders privacy and leads to the loss of properties and rights. Further, he points out that it is expected that professionals shall engage in principled conduct whether on their own behalf or at the request of employers, colleagues, clients, agencies or the profession.

\section{Challenges in Information Profession}

Organisations are confronted with many information management problems and issues. In many ways, the growth of electronic information (rather than paper) has only worsened these issues over the last decade or two (Quinn 2011). Common information management problems include: Large number of disparate (unlike) information management systems, little integration or coordination between the available information systems, direct competition between information management systems and work habits. Others are lack of a clear strategic direction for the overall technology environment, limited and patchy (irregular) adoption of existing information systems by staff, poor quality of information, including lack of consistency, duplication, and out-of-date information, little recognition and support of information management by senior management.

Other challenges include limited resources for deploying, managing or improving information systems, difficulties in changing working practices and processes of staff and internal politics impacting on the ability to coordinate activities enterprise-wide (Quinn 2005). While this can be an overwhelming list, there are practical ways of delivering solutions that work within these limitations and issues. Similarly Ocholla (2009), points outs some of challenges teaching information ethics in Africa as: lack of expertise, poor understanding or appreciation of information ethics, lack of space in information studies curricula and unsatisfactory professional practices to mention a few.

\section{Information Ethics Compliance}

Hence the above section explains the expected information profession is not what the individual does rather how he does the job. Moreover in teaching, guiding regulations of information professionals in Tanzania insist that must be aware and comply with the professional ethics. According to Tweve, (2012), the professional ethics include but not limited to:quality of information, positive mental attitude, effective communication, customer satisfaction, accurate and currently, privacy and secrecy, ownership, accountability, accessibility and competency. In information field a professionalism it to be competency on the information he/she provide to the people and avoid to make excuses on the poor information but find the solution to get the right information. This also can be applied to any teacher by providing accurate and relevant information to students and the society at large.

\section{Recommendations}

In order to make sure teacher education produce the required results, there is a need to introduce information ethics in teacher education programmes both in secondary and higher learning institutions. Apart from that, other recommendations to maintain professionalism to teacher, these should be considered:- 
Workshops and seminars. In door workshops and seminars, as well as university linkages and partnership activities such as faculty exchanges and joint curriculum development projects. The new stage of the Program focuses on incountry training of an increased number of master teacher trainers, while continuing to build the capacity of Tanzania teacher training institutions.

Mentoring. The allocation to each beginning teacher of an experienced teacher, specifically trained as a mentor; the mentor may provide emotional and professional support and guidance; in many U.S. states, induction is limited to the provision of a mentor, but research suggests that, in itself, it is not enough. Teaching involves the use of a wide body of knowledge about the subject being taught, and another set of knowledge about the most effective ways to teach that subject to different kinds of learner; it therefore requires teachers to undertake a complex set of tasks every minute. Many teachers experience their first years in the profession as stressful. The proportion of teachers who either do not enter the profession after completing initial training, or who leave the profession after their first teaching post, is high.

Continuous professional development. Because the world that teachers are preparing young people to enter is changing so rapidly, and because the teaching skills required are evolving likewise, no initial course of teacher education can be sufficient to prepare a teacher for a career of 30 or 40 years. Continuous Professional Development (CPD) is the process by which teachers (like other professionals) reflect upon their competences, maintain them up to date, and develop them further.

Quality Assurance. Quality in education relates to the quality of the work undertaken by a teacher, which has significant effects upon his or her pupils or students. Further, those who pay teachers' salaries, whether through taxes or through school fees, wish to be assured that they are receiving value for money. Ways to measure the quality of work of individual teachers, of schools, or of education systems as a whole, are therefore often sought. In most countries, particularly in Tanzania teacher salary is not related to the perceived quality of his or her work. Some, however, have systems to identify the 'best-performing' teachers, and increase their remuneration accordingly. Elsewhere, assessments of teacher performance may be undertaken with a view to identifying teachers' needs for additional training or development, or, in extreme cases, to identify those teachers that should be required to leave the profession. In some countries, teachers are required to re-apply periodically for their license to teach, and in so doing, to prove that they still have the requisite skills.

\section{Conclusion}

To ensure that students' behaviors do not jeopardize their future careers, educators must understand the activities that present ethical and professional issues and make every effort to educate students about appropriate behavior. For educators, perhaps the most familiar unethical issue facing students is that of academic dishonesty. The impact of academic dishonesty has long roots in working environment some of the impact are: corruption and bribery. Schools, colleges and universities have a great role on how to revisit their curriculum so as professionalism and ethics issues are inserted. Though both educators and students are largely familiar with the issues of academic dishonesty, it is an entirely new issue that poses the greatest threat to students' professionalism and one which has, on its face, nothing to do with students' academic performance or professional aspirations.

The paper concludes that information ethics and professionalism is one of the main items to consider introducing in teacher education curricular. The paper also concludes that features of professionalism such as specialized knowledge, competency, honesty and integrity, accountability, and confidentiality should be considered by teachers as well as information professionals in their day to day activities. The paper concludes by pointing out issues teachers and other professionals should comply with such as quality of information, positive mental attitude, effective communication, customer satisfaction, accurate and currently, privacy and ownership. However the paper concludes by noting that, information ethics and professionalism in Tanzania is a new filed but efforts are underway to make sure teachers in Tanzania benefit from Information ethics.

\section{Reference}

Amunga H.A, (2013), Introducing information ethics in the curriculum at Kenyatta University: views from lecturers and post-graduate students; in Innovation journal of appropriate librarianship and information work in Southern Africa. Number 46 pg 25.

Allen, K.P. (Spring, 2010). “ Classroom management, bullying and teacher practices” The Professional Educator 34 (1). 
Anangisye, W.A.L. \& Barrett, A. M. (2005), Professional Identity and Misconduct: Perspectives of Tanzania Teachers. Southern African Review of Education with Education with Production, 11, 5-22.

Anangisye, W. A. L (2006), Educating Teachers, the Ethical Dimension on Teacher Professionalism in Tanzania. Doctoral Dissertation, University of Edinburgh, Edinburgh.

Anangisye, W. A. L. (2010), Genesis Development, Practices and Problems of Teacher Training: The experience from Tanzania. In K.Karras \& Walhuter (eds.) International Handbook of Teachers Education World-wide (pp. 899-920). Athens: Atrapos Editions.

Barrett, A. (2005), Teacher Accountability in Context: Tanzania Primary School Teachers' Perceptions of Local Community and Educational Administration. Compare, 35 (1): 43-61.

Capurro, R., (2006), Towards an Ontological Foundation of Information Ethics. Ethics and Information technology, 8 (4), 157-186.

Donald L. McCabe, Linda Klebe Trevino, and Kenneth D. Butterfield, (1999), "Academic Integrity in Honor Code and Non-Honor Code Environments: A Qualitative Investigation", The Journal of Higher Education 70, no. 2 (March-April 1999), 213.

Hoel, H. \& Cooper, C.L.(2000), Destructive Conflict and Bullying at Work, Sponsored by the British Occupational Health Research Foundation, Manchester School of Management, UMIST (2000)

Ishumi A. G. (2009), Preparation of Education Professionals: Past, Present and Future Directions. Paper presented at the launching of the School of Education at the University of Dar es Salaam Tanzania.

Kaduma Ibrahim (2010), Maadili ya Taifa na Hatma ya Tanzania: Enzi kwa Mwalimu Julius K. Nyerere. Knowledge Printers and Publishers. Dar es Salaam.

Kigongo-Bukenya I., M. N. (2007), Towards Professionalism and Commitment in Africa: The Case for Theory and Practice of Information Ethics in Uganda. International Review of Information Ethics. Vol. 7 (09/2007).

Ocholla D., (2009), Information Ethics Education in Africa: Where do we stand? The International Information and Library Review. 42, 79-88.

Schnall, R.S. (2009). When Teachers Talk: Principal Abuse of Teachers / The Untold Story. Goldenring Publishing.

Tweve, J. T. (2012), "Practices of Teaching Information Ethics in Tanzania". Paper Presented at African Network for Information Ethics (ANIE) Conference, $3^{\text {rd }}$ to $7^{\text {th }}$ September 2012 Held Pretoria, at Kievits Kroon Hotel.

Quinn, Michael J. (2011), Ethics for the Information Age, $4^{\text {th }}$ ed. Boston, MA: Addison-Wesley. 